the Finance Officer, is pored over by the Honorary Officers, and is subjected to detailed examination by the Executive and Finance Committee, before being debated at the Council and ultimately put to the Annual Meeting. Any thoughts which I might harbour of doubling the subscription rate would undoubtedly be picked up and thrown out long before I had managed to put such novel ideas into practice.

\title{
Who pays for continuing care of the chronically ill?
}

The Public Policy Committee wishes to draw the attention of members of the College to an important recent judgement by the Parliamentary Commissioner for Health (Ombudsman). He ruled, in the case of a woman chronically disabled by a head injury and judged by her consultant as likely to "need sustained nursing care for the rest of her life", that the local Health Authority had a duty to continue to provide care at no cost to the woman or her family. He took into account the Health Authority's responsibility, as recently amplified by the NHS Management Executive, that "if in a doctor's judgement a patient needs NHS care then there is a duty on the health service to provide it without charge within the resources available". The issue was well highlighted by the BMJ's Parliamentary correspondent,
John Warden (BMJ, 2 November, 1991, Letter from Westminster, 303, 1092). A recent speech by the Minister for Health, Stephen Dorrell (3 December, 1991 - Written Answers, p. 114) has confirmed the position and the recent report of the Select Committee on the Fourth Report of the Social Security Committee on 'The Financing of Private Residential and Nursing Home Fees' (HMSO, £8.90) provides extremely relevant background. The Ombudsman's decision is likely to have a profound influence on the future funding of care for the elderly and chronically ill.
Dr R. G. JONES

Secretary

Public Policy Committee

\section{Report of a seminar on psychiatric provision for people with long-term mental illness*}

\author{
Douglas G. Fowlie, Chairman, Social Community and Rehabilitation Section
}

This meeting was part of the IHSM series Medicine for Managers. Forty-four members of the IHSM participated. Also present were psychiatric trainees and members of the medical press. The theme for the day was to explore the uncertainty about how to meet the needs of people disabled by long-term mental illness.

Professor Steven R. Hirsch introduced the topic, clarifying the difficulties of data collection on local epidemiology and emphasising the continuing uncertainty about rates of seriously disabling mental

\footnotetext{
*Arranged for the Institute of Health Services Management by the Social Community and Rehabilitation and General Psychiatry Sections of the Royal College of Psychiatrists at Keele University on 9 October 1991.
}

illness. Despite difficulties in quantifying the problems, he concluded that long-term mental illness continues to generate sufficient difficulties for a percentage of patients to require long-term care.

Dr Peter Liddle used case examples to emphasise that some patients with protracted mental illness persistently behave in a seriously disruptive manner with consequences that cannot easily be absorbed in a community setting. He spoke about the multifactorial origins for such behaviour with a definite interaction between illness and adverse social circumstances. He outlined methods of assessing the scale of these problems and opened the debate about meeting those needs, when large mental hospital sites were closing. He emphasised the need for: 
(a) adequate numbers of staff

(b) grounds that provide spacious buffer zones

(c) homely accommodation for developing domestic skills

(d) proximity to community facilities

(e) an opportunity for work or meaningful diversion in a supervised setting

(f) ready access to an acute secure ward to contain any episodes of dangerous behaviour.

The association between these problems and relatively young age confirms that this provision is required during the adult's life.

Dr D. G. Fowlie described a 25 year follow-up study of 425 residents who had been through a hospital staffed hostel. In those 25 years the patient population yielded 29 deaths by suicide. The relative risk factor was 20 . Given the fact that suicide is underreported and that probable suicides and violent deaths add to the risk, long-term mental illness is a life-threatening condition. Deaths by suicide occurred anything up to ten years after residents left the hostel. The audit highlighted the requirement for clinical and statutory services to remain in contact with people suffering from chronic psychotic illness over a prolonged period.

Dr Trevor Turner spoke about the relationship between homelessness and mental illness, emphasising that individuals with long-term mental illness lack motivation and personal organisation and as a result are severely disabled. Catchment boundaries may work against meeting the needs of this population. The spectrum of services required with long-term supervised hostel accommodation, housing support teams, community care clinical teams who can be assertive and appropriate welfare benefits do not of ten coalesce. He emphasised the low priority afforded to people with long-term mental illness when scarce accommodation is being re-allocated or redeveloped.

The special problems relating to elderly people with associated mental illness were outlined by Dr David Jolley. He emphasised the potential for exploitation and neglect created by the shift towards nursing homes provided by the private or voluntary sector since contact with clinical services and the safeguards associated with Responsible Medical Officers were often overlooked. He gave the results of a comprehensive audit of old age psychiatry services. Heconcluded that special arrangements in Health Service planning are needed to protect the vulnerable, dependent and disturbed patients with mental illness in old age. He confirmed that concerns were shared by the Alzheimer's Disease Society, Age Concern and the Association of Community Health Councils.

Drs Tom Burns and Tony Kendrick presented a paper on the role of the general practitioner in the care of long-term mental illness. Dr Kendrick clarified the respective roles of primary health care and community psychiatric teams and talked about estimating the numbers of long-term mental illness patients in a general practice. The uneven distribution of these patients and the variable attitudes of general practitioners determined whether both physical and psychiatric needs generated by people with long-term mental illness were met. He talked about the paucity of practice policies to care for the long-term mentally ill and the difficulties in getting community psychiatric help to practices in inner cities. He made a plea for:

(a) training of general practitioners in the care of the long-term mentally ill

(b) practice based registers

(c) regular review of patients physical and mental states.

He dwelt on the constraints generated by both General Practice Fund Holding and contracting for services.

Dr Graham Thornicroft talked about the prediction of psychiatric service utilisation by a population and determining the location of patients with longterm mental illness. His research highlighted the uncertainties in defining vulnerability and the difficulties in meeting need by dispersed clinical services.

Professor J. L. Cox urged service planners to ensure that patients with long-term mental illness were in touch with adequately trained health professionals who could also support their carers. He emphasised that there were serious gaps in rehabilitation services and that other health professionals may not be sufficiently trained in the clinical understanding of long-term mental illness. The requirements for additional training and continuing medical education were clarified. Case management was discussed. Money presently devoted to psychiatric service provision should be ring-fenced in order to allow knowledgeable staff to work in local settings.

A detailed discussion with delegates led to general conclusions:

(a) that psychiatric service planning did not always adequately consider the needs of people with long-term mental illness

(b) the continued accumulation of people with long-term problems must be acknowledged

(c) increased numbers of trained staff were necessary to work in dispersed settings

(d) the constraints occasioned by General Practice Budget Holding and contract setting necessitated accurate local data collection and the establishment of case registers to identify the health care needs of this group vital.

This seminar was preceded by a press release. The same theme is being pursued at the Social, Community and Rehabilitation Section Annual Scientific Meeting at the Royal College of Physicians on Monday 23 March 1992. 